\title{
Analysis of regional innovation environment factors within the institutional approach
}

\author{
Galina Snigireva ${ }^{1, *}$, Irina Sennikova ${ }^{1}$, Elena Karanina ${ }^{1}$, Alexander Bakhtimov ${ }^{1}$, and \\ Larisa Domracheva ${ }^{1}$ \\ ${ }^{1}$ Vyatka State University, Department of Finance and Economic Security, 610000 Kirov, \\ Moskovskaya st., 36, Russia
}

\begin{abstract}
The article deals with a new approach to the assessment of regional innovation environment factors. The approach is based on the assessment of three fundamental factors: the legal, infrastructural, and economic ones. The theoretical significance of the study lies in a contribution to the development of techniques for the assessment of development factors of the innovation environment of regions on the basis of an index method, taking into account expert opinions of innovators. The purpose of the research was to develop a mechanism for the regulation of the development of the regional innovation environment on the basis of the author's technique - the PRIM index. The methods of research included the economic and statistical methods, methods of expert evaluation, the correlation and regression analysis, and the index method. The result of the research is the formation of an organizational and economic mechanism for the regulation of the development of the regional innovation environment on the basis of the PRIM index method that takes into account the assessment of innovators in order to increase the level of the regional innovation potential as a factor of social and economic development of the subjects of the Russian Federation. Based on this mechanism, the authors proposes an algorithm for managerial decision-making aimed at improving the management of the innovative potential of regions.
\end{abstract}

\section{Introduction}

What is currently needed for an innovative, qualitatively new development of the state is the formation and maintenance of an environment that would facilitate the creation and introduction of things aimed at increasing the level of the region's innovation capacity. Due to the economic sanctions imposed by western countries, Russia has to develop and introduce innovations in key areas of its economy and social life all by itself. Formation and maintenance of an environment that facilitates the creation of innovations is required for an innovative, qualitatively new development of the state. This, in its turn, is a natural consequence of the ongoing transition from the economy based on classical factors of production (labor, land, capital) to the economy based on knowledge and innovation [1-4].

\footnotetext{
*Corresponding author: snigireva_g_d08@mail.ru
} 
We would like to mention that the concept of innovation milieu was considered within the framework of institutional economic theory, where the institution is understood as the "rules of the game" in society or, more formally, the man-made restrictive framework that organizes behavior between people. The institutional environment in the national innovation system is a set of interrelated and interdependent legislative, political, economic, legal and socio-cultural institutions that determine the incentives for innovation.

Taking into account the institutional approach and the concepts studied, the author proposes to divide the factors of the innovation environment into internal and external. In our opinion, this combination is a fundamental condition for effective innovation (Fig. 1).

The author combined many external (exogenous) factors of the innovation environment into two groups:

1. direct factors directly affect the work of the innovator (laws and institutions of state regulation, suppliers of raw materials, equipment, energy, components, consumers of products, competitors, both existing and potential engaged in the production of similar products and substitute goods; trade, financial, transport and other intermediaries);

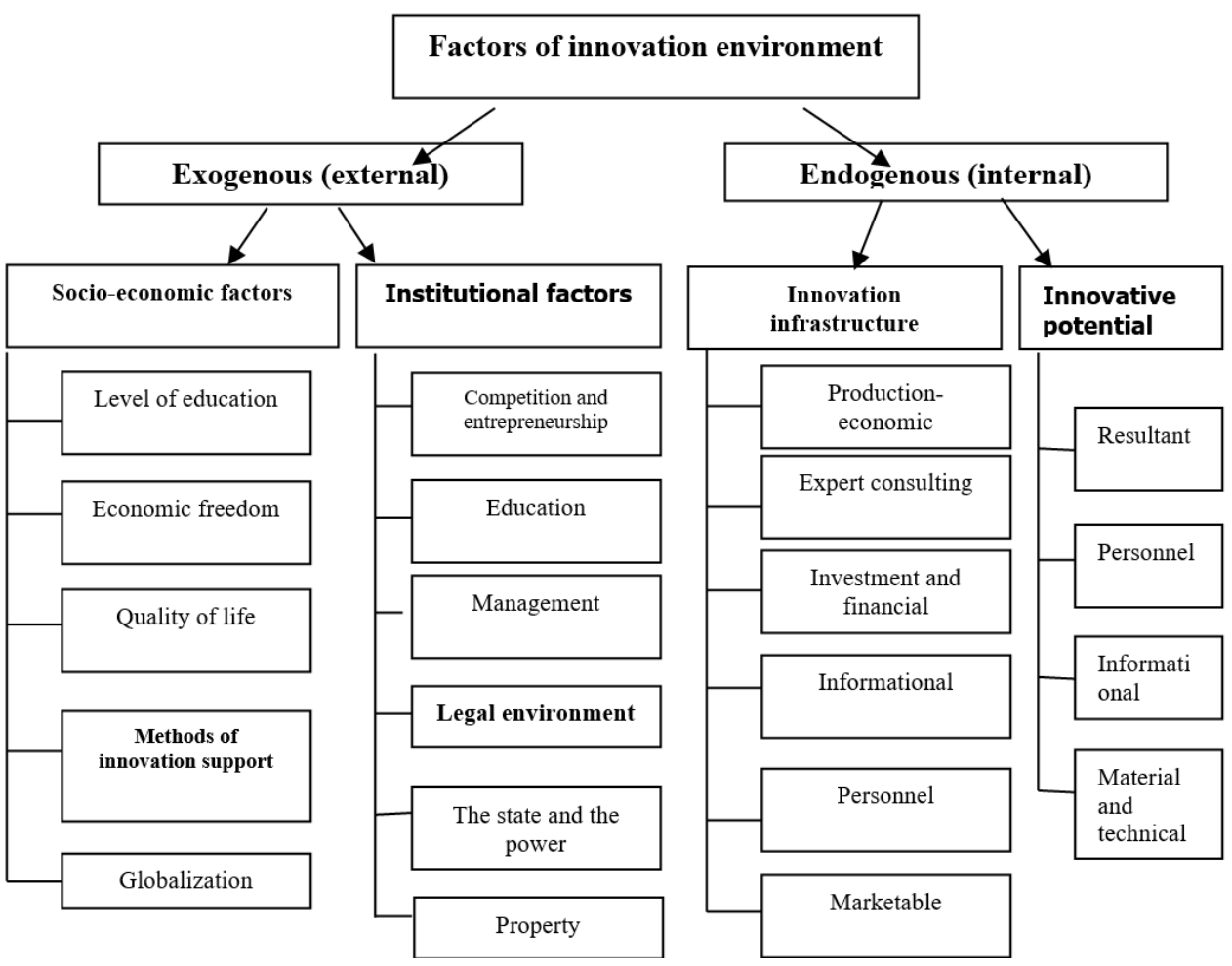

Fig. 1. Formation of innovation environment factors (compiled by the author).

2. indirect factors indirectly affect the work of the innovator (state of the economy, scientific and technological progress, political, demographic, natural and cultural factors).

The regions of our country are to actively develop their innovation capacity, to create necessary conditions for the development and introduction of innovations, therefore a research into the assessment and management of the innovation capacity of Russia's territories (regions) is particularly relevant now. Different approaches to defining resources as the factors for assessing the effective use of the innovation capacity exist at the present stage of the economic science development. Various categories are used for this: 
"production capacity", "resource capacity", "economic capacity", "availability of objective production conditions" [5].

In this regard, the objective of this research was to develop a mechanism for regulating the development of a regional innovation environment through the perfection of the methods for the assessment of its factors in order to increase the level of the innovation capacity of Russian regions. All the existing methods for the assessment of the innovative environment factors of regions that are normally used in research are based on statistics and do not take into account the "human factor" as a system of parameters for the analysis of the direct participants in innovation processes (the innovators) in terms of the conditions created for their successful operation $[10,16]$. The new method takes into account the innovators' opinions, and on the basis of their assessments, it will improve the quality of innovation development strategies of the subjects of the Russian Federation that can become the basis of the modernization process of the Russian economy at the moment.

\section{Materials and Methods}

The majority of both foreign and domestic methods evaluate the factors and conditions of the innovation environmental of a region through statistics. The existing treatments are not sufficient for determining the region's innovation environment factors in terms of the principle of their triunity [7, 15] (Fig. 2). Therefore we have identified the following regional innovation environment factors:

1. The legal norms regulating innovation activities (PR - from pravovoy - Russian for legal) - a list of the main legislative acts and regulatory documents in the sphere of science and innovation.

2. The infrastructure facilities that support and develop innovations (I) - a set of structures to provide the conditions required for innovation activities and functioning of innovation processes (business incubators, technology parks, business support funds, etc.).

3. Methods for the support of innovation activities (M) - a set of regulatory government measures (both administrative and economic ones) that are aimed at the development of innovation activities in the territory.

The proposed institutional components (factors) of the innovation environment of a region coexist, complement and condition each other.

Taking the above into account, we propose a more specific definition of the innovation environment factors of a region - a set of conditions for the development of innovation activities of a region on the basis of legal norms (PR), infrastructure (I) and methods of support (M) in terms of the awareness level, their importance and effectiveness for innovators in a competitive market environment [6].

A developed institutional environment is among the conditions for creating a favorable environment for innovation development. That is why one of the main objectives now is to create conditions and factors for the most effective implementation of them.

Research has made it possible to identify the main stages in the analysis and evaluation of innovation environment factors of a region using the method called the PRIM index [2, 12].

At the first stage of a research, source data are prepared, a statistical analysis of the development level of the region's innovation capacity is carried out and the generalization of the information on the above factors is done.

The second stage involves the development of questionnaires that allows assessing the awareness level, importance and effectiveness of the innovation environment factors of the region that are listed in them.

At the third stage, a survey of the respondents (innovators) who are stakeholders of the innovation process in the region is organized. 
The homogeneity of the participants' assessments, as well as the reliability of the research are largely confirmed by calculating the variation coefficient in the method proposed by the author.

The fourth stage consists of processing the information, making summary tables, charts and calculating the sub-indices (NPA, OII, and MPID). The relation of the sub-indices to innovation capacity indicators of regions is determined by means of correlation analysis.

In view of the theoretical research, an author's technique has been developed for the assessment of innovation environment factors that makes it possible to take into account innovators' assessments in the regions of Russia [3].

Research in this area made it possible to identify a new approach to the assessment of the innovation capacity of a region that is called the PRIM index method.

\begin{tabular}{|c|c|c|}
\hline & Factors of innovation environment in the region & egion \\
\hline $\begin{array}{l}\text { 1. LEGAL regulations } \\
\text { governing innovation }\end{array}$ & $\begin{array}{l}\text { 2. I-infrastructure } \\
\text { facilities } \\
\text { support and development } \\
\text { innovations }\end{array}$ & $\begin{array}{l}\text { 3. } M \text { - methods of } \\
\text { innovation support }\end{array}$ \\
\hline $\begin{array}{l}\text { 1.1. A law on industrial } \\
\text { policy } \\
1.2 . \quad \text { Law on taxation of } \\
\text { organizations and enterprises } \\
1.3 \text {. The law on } \\
\text { regulation of investment } \\
\text { activities } \\
1.4 \text {. Law on science and } \\
\text { science and technology policy } \\
1.5 \text {. Law on the } \\
\text { development of small and } \\
\text { medium-sized enterprises } \\
1.6 . \quad \text { The law on the } \\
\text { development of innovative } \\
\text { activities } \\
1.7 \text { Intellectual property } \\
\text { protection legislation } \\
1.8 \text { Long-term strategy } \\
\text { of socio-economic development } \\
\text { of the region } \\
1.9 . \quad \text { Small business } \\
\text { support and development } \\
\text { program } \\
1.10 . \quad \text { Program to improve } \\
\text { the investment climate and } \\
\text { attract investment and new } \\
\text { technologies in the economy of } \\
\text { the region }\end{array}$ & $\begin{array}{l}\text { 2.1. Centre for scientific and } \\
\text { technical information } \\
2.2 \text {. Center for research } \\
\text { projects } \\
\text { 2.3. Business incubator } \\
\text { 2.4. Technopark } \\
\text { 2.5. Center for innovative } \\
\text { development of } \\
\text { entrepreneurship } \\
\text { 2.6. Technology transfer } \\
\text { center } \\
\text { 2.7. Information and } \\
\text { innovation center } \\
\text { 2.8. Center of exhibition and } \\
\text { fair activity } \\
\text { 2.9. Outsourcing services } \\
\text { center } \\
\text { 2.10. Fund for support of } \\
\text { small and medium enterprises }\end{array}$ & $\begin{array}{l}\text { 3.1. Subsidizing part of } \\
\text { interest rates on loans } \\
\text { attracted by ID entities } \\
\text { 3.2. The subsidization of } \\
\text { leasing payments under } \\
\text { leasing contracts of } \\
\text { constituent entities of ID } \\
\text { 3.3. The provision of budget } \\
\text { investments to the entities ID } \\
\text { 3.4. Provision of tax benefits } \\
\text { 3.5. Provision of investment } \\
\text { tax credit } \\
\text { 3.6. Participation in } \\
\text { exhibitions and fairs } \\
\text { 3.7. Venture investment of } \\
\text { innovative projects of small } \\
\text { businesses } \\
\text { 3.8. Grant support for certain } \\
\text { categories of citizens who } \\
\text { want to organize their own } \\
\text { business } \\
\text { 3.9. Information and } \\
\text { consulting support of ID } \\
\text { subjects } \\
\text { 3.10. Preferential use of } \\
\text { property in regional } \\
\text { (municipal) ownership }\end{array}$ \\
\hline
\end{tabular}

Fig. 3. Factors of innovative environment of the Kirov region (compiled by the author).

The PRIM index method and the sub-indices that make up its foundation is based on the following five principles:

a) focus on innovators' opinions in the region;

b) the triunity of the significant factors of the innovation environment in the region: regulatory acts, innovation infrastructure facilities, and methods for the support of innovation activities; 
c) homogeneity of innovators' assessments and judgments concerning the innovation environment factors of the region;

g) consistency of the PRIM index method using statistical, economic-mathematical methods, as well as the method of expert assessment;

d) inclusion of the PRIM index method in the process of decision-making on the development of innovation environment with the purpose of increasing the innovation capacity of the region.

The essence of the method lies in the fact that such factors as: PR - legal regulation of innovation activities; I - the infrastructure of innovation activities; $\mathrm{M}$ - methods for the support of innovation activities - allowed us to determine the following sub-indices $[1,11]$ :

1. the sub-index INPA to evaluate the awareness and perception, by innovators, of the key regulatory acts at the level of a subject of the Russian Federation;

2. the sub-index OII to determine the awareness level of innovators and their assessment of operability of innovation infrastructure facilities in their subject of the Russian Federation;

3. the sub-index MPID to determine the awareness level of innovators and their assessment of the effectiveness of methods for the support of innovation activities in their region.

The PRIM index is calculated as the average of the sub-indices INPA, OII, and MPID. We use the additive convolution rather than the multiplicative one as it is more applicable to the criteria (in this case the sub-indices) that are homogeneous in their meaning and close in the scale of their values. Weighing factors were not used since determination of weighting factors results in a high level of uncertainty and, in addition, the sub-indices are equal in their importance.

\section{Results}

The research to assess innovation environment factors of a region using the PRIM index method employed target sampling. During an interview, the respondent was asked, according to the questionnaire developed for each region, to assess their awareness, as well as to quantify the significance and to assess, by the given scale, the effectiveness of the regulatory acts, the infrastructure facilities and the methods for the support of innovation activities in their region. The research toolkit (in the form of a structured questionnaire) was developed in view of the region's particular features concerning the sub-indices NPA, OII and MPID $[8,9]$.

After processing the questionnaires, we calculated the coefficients of awareness, significance and the assessment of effectiveness concerning innovation regulatory acts, innovation infrastructure facilities and methods for the support of innovation activities. In addition, we processed the data on the problems of the development of innovation environment factors in the region followed by ranking them in order of significance for various groups of innovators [14,18]. Eventually, the results obtained allowed the author to calculate the values of the sub-indices NPA, OII and MPID on the basis of which the PRIM index was determined for each examined region. The PRIM index takes a value between 0 and 1. If the PRIM index or the sub-indices NPA, OII and MPID take the values between 0 and 0.33 , this means a low level; between 0.34 and 0.67 - a middle level, and between 0.68 and 1 - a high level of the development of innovation environment factors in the region.

The research resulted in the following values of the sub-indices of the PRIM index method for the regions of Russia. The values for the Kirov region are shown in Fig. 3.

The values of the sub-indices are the following: for potential innovators $-0.62,0.64$, and 0.61 ; for representatives of business $-0.55,0.63$, and 0.56 ; for organizers of innovation activities $-0.66,0.71$, and 0.69 . 
In order to determine the uniformity of innovators' judgments and to verify the reliability of the developed technique for managerial decision-making, the coefficients of the variation of innovators' assessments were calculated. The average value of the variation coefficient in the context of sub-indices is the following: INPA -23.5 , OII -24.9 , and MPID - 23.3.

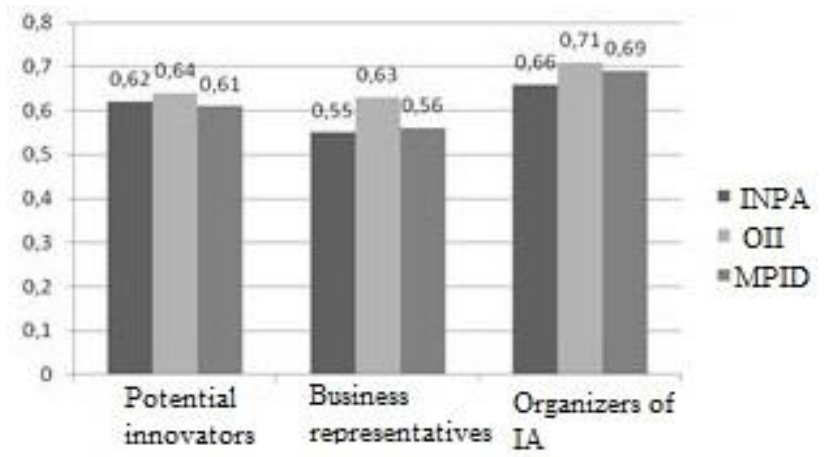

Fig. 3. Values of the sub-indices of the PRIM index method for the Kirov region.

If the variation coefficient is less than $10 \%$, the variability of the variational series is considered to be insignificant, between $10 \%$ and $20 \%$ - medium, more than $20 \%$ but less than $33 \%$ - significant. If the variation coefficient exceeds $33 \%$, it indicates heterogeneity of the information and the need to exclude the highest and the lowest values. The optimum value of the variation coefficient should not exceed $33 \%$.

Calculations reveal the different levels of development of the innovation environment factors in each region that form the basis of managerial decision- making in accordance with available resources and forecast results. At the same time, the factors that are proposed for assessment on the basis of innovators' assessments of the examined region possess the property of homogeneity, and therefore the value of the PRIM index is reliable enough in practical calculations for the analysis and assessment of the development factors of the innovative environment of the region.

\section{Discussion}

The created method for the assessment of regional innovation environment factors on the basis of the results of the research by the PRIM index method can be used in the process of managerial decision-making in the regions. Certain provisions of the study can be applied for the elaboration of innovation development programs of regional economies and of regional development strategies. The data from innovators' assessments and the calculation of sub-indices can provide managers of the regional level with an indication of which innovation environment factors (regulatory support, innovation infrastructure facilities, methods for the support ща innovation activities) are less developed for innovators, and which are more. This will help to properly prioritize, allocate resources, and identify the areas of innovation development in the region.

The results of the research can be used:

- by research and educational institutions for the training of graduate and postgraduate students and refresher courses and advanced training students in the socio-economic sphere in the following academic disciplines "Regional Economics", "Institutional Economics", "Regional Governance and Territorial Planning", "Government Investment Policy", "Public and Municipal Administration", "Innovation Management", etc.; 
- by the personnel of the facilities for the support and maintenance of innovation activities in the region to analyze the opportunities and the ways of their development (business incubators, research institutions, innovation centers, etc.);

- by the subjects of innovation entrepreneurship in the region (entrepreneurs, young researchers);

- by local and regional authorities to create and develop innovation infrastructure in the region, to elaborate economic instruments for the support of innovation activities and regulatory documents in the sphere of innovation activities in the subject of the Russian Federation.

\section{Acknowledgments}

The research was conducted within the framework of the grant project "Conditions, factors and indicators of modernization development in the regions of Russia: research with application of qualitative and quantitative methods", "Instrumental approaches to the assessment of the modernization development of Russia: indices, regional dimensions and recommendations." The project was supported at the $4^{\text {th }}$ open competition of projects of non-profit non-governmental organizations that have social importance in the field of research and monitoring the state of the civil society "Development problems of the contemporary Russian society" (Moscow), issued by the Institute for Public Planning, in accordance with the decree of the President of the Russian Federation No.300-rp.

\section{References}

1. G.D. Snigireva, I.L. Sennikova, Fundamental Research 5, 653-657 (2015)

2. I.L. Sennikova, G.D. Snigireva, Issues of the Regional Economics 3(24), 42-50 (2015)

3. I.L. Sennikova, Materials of the II intern. scientific -practical conference, Vyatka, 2, 541-548 (2016)

4. G.D. Snigireva, M.A. Kazakova, O.A. Mironova, M.V. Palkina, V.I. Bespyatyh, Espacios 38 (54), 30 (2017)

5. G.D. Snigireva, Materials of the II intern. scientific -practical conference, Vyatka 2, 556-560 (2016)

6. E. Balatsky, Society and Economy 1, 3-20 (2010)

7. I.L. Balezina, V.N. Yakimets, Caspian region: politics, economy, culture 4(29), 54 - 63 (2012)

8. I.L. Balezina, V.N. Yakimets, Political Expertise: Politeks 7(3), 5-22 (2012)

9. I.L. Balezina, V.N. Yakimets, A.A. Shirobokova, Bulletin of Irkutsk State Technical University 5(64), 182-191 (2012)

10. O.V. Valiyeva, Institutional environment of innovation activities, tutorial (Novosibirsk State University, Novosibirsk, 2011)

11. O.N. Vladimirova, Regional economy: theory and practice 27, 26-33 (2011)

12. E. Karanina, D. Loginov, IOP Conf. Series: Earth and Env. Science, 90, 012087 (2017)

13. E. Karanina, D. Loginov, Procedia Engineering 165, $972-979$ (2016)

14. R. Kuchukov, Economist 1, 20-29 (2010)

15. E.P. Lisichenok, Bulletin of Polotsk State University 6, 21-26 (2011)

16. C. Freeman, The Economics of Industrial Innovation (Printer, London, 1997) 